\title{
TINDAK TUTUR DIREKTIF PEDAGANG DI PASAR TANAH ABANG
}

\author{
Rini Sriyanti \\ Program Studi Informatika Universitas Indraprasta PGRI \\ abib.arsyilla@yahoo.com
}

\begin{abstract}
Abstrak
Peristiwa tindak tutur yang terjadi antara penjual dan pembeli di pasar mempunyai peranan yang sangat penting, yaitu menyampaikan maksud dan tujuan berbagai pihak, dimana bahasa sebagai sarana agar tercapai kesepakatan. Tujuan penelitian ini adalah untuk mendeskripsikan bentuk tindak tutur dan jenis tindak tutur yang digunakan pedagang di Pasar Tanah Abang. Subjek penelitian ini adalah tuturan pedagang di Pasar Tanah Abang. Sampel percakapannya di ambil sebanyak 10 percakapan. Pengumpulan data penelitian ini dilakukan dengan metode simak. Data di simak dengan menggunakan rekaman dan catat. Sememntara itu analisis data digunakan untuk kriteria penentu jenis tindak tutur. Hasil penelitian dapat dijabarkan sebagai berikut, 1) bentuk tindak tutur yang digunakan pedagang di Pasar Tanah abang yaitu tindak tutur representative, tindak tutur direktif, tindak tutur ekspresif, tindak tutur komisif, dan tindak tutur deklaratif, 2) jenis tindak tutur, yang lebih banyak digunakan yaitu tindak tutur direktif, dimana tindak tutur ini bermaksud mengajak dan mempengaruhi pembeli.
\end{abstract}

Kata kunci : Jenis tindak tutur pedagang

\begin{abstract}
Abstrac
The event of speech act that happen between buyer and seller in the market have important role, is to deliver the intention of some parties. Buyer and seller have same language as a means to deliver the intention in order to get the deal. The purpose of research is to describe form speech act and kind of speech act are using by seller and buyer to communication in Tanah Abang market. The object of research is speech act. The sample of dialogues are taking from 10 dialogues. The collecting of data research is observation attentively. The data are getting from note and record. Baside that, we areusing kind of speech act analysis of data. The result of research can be eplain, such as: 1) Tanah Abang are representative, directive, expressive, commissive, and declarative speech act, 2) Most of seller are using directive speech act in communication to persuade and influence the buyer at Tanah Abang market.
\end{abstract}

Keywords: the type of speech act of the trader

\section{PENDAHULUAN}

Bahasa merupakan alat komunikasi sosial manusia, di mana bahasa memegang peranan penting bagi kita yaitu sebagai alat komunikasi untuk menyampaikan informasi. Melalui bahasa seseorang dapat mengungkapkan ide-ide dan perasaannya. [1] Bahasa adalah alat untuk berinteraksi atau komunikasi dalam arti untuk menyampaikan pikiran, gagasan, konsep, atau juga perasaan.

Hal ini berarti segala sesuatu yang ada dalam fikiran manusia disampaikan melalui bahasa, baik bahasa tulis maupun bahasa lisan. Selain itu bahasa memerlukan konteks untuk memperjelas maksud dan maknanya, sedangkan konteks akan memiliki makna jika terdapat tindak tutur bahasa di dalamnya. [2] Konteks adalah sebuah dunia yang di isi orangorang yang memproduksi tuturan-tuturan.

Peristiwa tutur ini pada dasarnya merupakan rangkaian dari sejumlah tindak tutur yang terorganisasikan untuk mencapai suatu tujuan. [3] tindak tutur merupakan gejala individual, bersifat psikologis dan keberlangsungannya ditentukan oleh kemampuan bahasa si penutur. Teori tindak tutur lebih dijabarkan oleh para lingusitik, [4] secara pragmatis, setidak-tidaknya ada tiga jenis tindakan yang dapat diwujudkan oleh seorang penutur dalam melakukan tindak tutur yakni (a) tindak lokusi (melakukan 
tindakan untuk menyatakan sesuatu), (b) tindak ilokusi (melakukan suatu tindakan dalam menyatakan sesuatu), (c) tindak perlokusi (melakukan sesuatu tindakan dengan mengatakan sesuatu). [5] Teori tindak tutur ini dibagi menjadi lima jenis tindak tutur :

1. Tindak tutur representatif yaitu tindak tutur yang mengikat penuturnya kepada kebenaran atas apa yang dikatakannya, misalnya menyatakan, melaporkan, menunjukkan.

2. Tindak tutur direktif yaitu tindak tutur yang dilakukan penuturnya dengan maksud agar si pendengar atau mitra tutur melakukan tindakan yang disebutkan di dalam ujaran itu, misalnya menyuruh, memohon, menuntut, menyarankan,dan mengajak.

3. Tindak tutur ekspresif adalah tindak tutur yang dilakukandengan maksud agar ujarannya diartikan sebagai evaluasi mengenai hal yang disebutkan di dalam ujaran itu, misalnya memuji, mengucapkan terima kasih,mengritik.

4. Tindak tutur komisif adalah tindak tutur yang mengikat P-nya untuk melaksanakan apa yang disebutkan di dalam ujarannya,misalnya berjanji dan bersumpah.

5. Tindak tutur deklratif adalah tindak tutur yang dilakukan $\mathrm{P}$ dengan maksud untuk menciptakan hal (status, keadaan, dan sebagainya) yang baru, misalnya memutuskan, membatalkan, melarang, mengizinkan, memberi maaf.

Dalam bertutur, penutur dan mitra tutur saling menyadari bahwa ada kaidah-kaidah yang mengatur tindakannya. Tuturan tidak hanya berfungsi untuk mengatakan atau menginformasikan sesuatu, tetapi dapat dipergunakan untuk melakukan sesuatu. Pembicaraan atau tuturan dalam suatu percakapan, yang terjadi dapat berbentuk langsung dan tidak langsung. Percakapan yang mengandung tindak tutur dapat terjadi pada transaksi jual-beli.
Pengertian transaksi dalam KBBI adalah persetujuan jual-beli dalam perdagangan antara dua pihak, sedangkan jual-beli merupakan suatu transaksi yang di lakukan pedagang dan pembeli, kemungkinan akan banyak terjadi tindak tutur, baik itu langsung maupun tidak langsung, terutama ketika pedagang dan pembeli melakukan tawar-menawar untuk mencapai suatu kesepakatan harga

Konteks adalah sesuatu yang menjadi sarana pemerjelas suatu maksud. [6] Sarana itu terbagi menjadi dua macam, yaitu 1) bagian ekspresi yang dapat mendukung kejelasan suatu maksud (cotext); 2) berupa situasi yang berhubungan dengan suatu kejadian (context).

Tempat transksi jual-beli yang dipilih adalah Pasar Tanah Abang dimana pasar ini merupakan pusat perbelanjaan terbesar di Asia Tenggara, dimana banyak terdapat transaksi jual -beli dan tawar-menawar harga barang, sehingga banyak terjadi interaksi tuturan atau tindak tutur. Penelitian Tindak Tutur ini berfokus pada; 1) Bagaimana wujud tindak tutur yang digunakan, 2) Apakah jenis tindak tutur yang dominan digunakan pedagang pasar Tanah Abang. Penelitian ini bertujuan untuk mengetahui bentuk tuturan dan jenis tindak tutur yang digunakan pedagang Pasar Tanah Abang.

\section{METODE}

Pendekatan yang digunakan dalam penelitiaan Tindak Tutur ini adalah pendekatan pragmatik, yaitu sebuah kajian bahasa bagi penggunaanya. Pemilihan pendekatan ini karena yang menjadi objek dalam penelitian ini adalah bidang kajian pragmatik, sedangkan subjek penelitian ini adalah pedagang pasar Tanah Abang.

Metodologi yang digunakan adalah kualitatif deskriptif yaitu tidak berupa angka-angka tetapi berupa kata-kata tertulis atau lisan. Dalam penelitian ini 
peneliti sebagai instrumen kunci, dalam pengumpulan data maupun analisis data karena keterlibatan langsung penulis dalam menganalisis tindak tutur pedagang pasar tanah abang dalam komunikasi lisannya sehari-hari. Sumber data dalam penelitian ini adalah tuturan yang disampaikan pedagang kepada pembeli di pasar Tanah Abang.

Teknik penelitian yang digunakan adalah teknik rekam, simak dan teknik catat [7]. Teknik rekam adalah pemerolehan data dengan cara merekam tuturan dalam pemakaian bahasa lisan dengan alat tipe recorder. Teknik simak adalah teknik yang bekerja dengan cara menyimak. Teknik catat adalah data-data yang kita dapat kita catat dalam kartu data.

\section{HASIL DAN PEMBAHASAN}

Penelitian ini dilaksanakan pada tanggal 11-13 Januari 2012 di pasar tanah abang, jakarta pusat. Penelitian ini penulis pusatkan pada pedagang pasar tanah abang. Ada pun fokus yang diteliti dalam penelitian ini adalah tindak tutur pedagang kaki lima di pasar tanah abang.

Dimana landasan dari penelitian ini diambil dari teori tindak tutur [5] dan membaginya menjadi lima jenis tindak tutur:

1. Tindak tutur representatif

Hal ini dapat kita temukan dalam tindak tutur pedagang di pasar tanah abang:
a) Pedagang $\mathrm{A}$ :
"barang mangga dua itu mbak,kalo di malle itu seratus lebih lo mbak" ( menyatakan)
b) Pedagang B : "jamnya tahan air kak,dibawa berenang, mandi gak bakal mati". (menunjukkan)
c). Pedagang $\mathrm{C}$ : "bahannya bagus kak, kulit asli itu, dijamin kakak gak bakal merasa rugi". (melaporkan)
d). Pedagang D :

"iko modalnyo se limo puluh ni, bahan stret ko mah ni”. (menyatakan)

e). Pedagang E :

"itu aja modalnya 30, bagaimana saya menjualnya 25 kak rugi mah yang ada saya. (menyebutkan)

f). Pedagang F : "boleh dilihat, ini buktinya jam yang sama saya rendam di air dari tadi. (menunjukkan)

Berdasarkan hasil analisis data dapat diketahui bahwa tindak tutur representatif ini digunakan oleh pedagang di pasar tanah abang dalam berkomunikasi dengan pembeli.

2. Tindak tutur direktif

Hal ini dapat kita temukan dalam tindak tutur pedagang di pasar tanah abang:

a) Pedagang $\mathrm{A}$ :

"silahkan neng pilih aja jam tangannya, barisan depan dua lima, tengah kasih tiga puluh, dan belakang empat lima”. (mengajak)

b) Pedagang $\mathrm{B}$

"boleh di uji, lihat ini mbak jamnya saya rendam di air, gak mati. (menantang)

c) Pedagang $\mathrm{C}$ :

"kalo jamnya mati, uang kakak saya kembalikan". (menantang)

d). Pedagang D : "dicoba aja dulu kak, kakinya nomor berapa? nah tu pas banget kan mbak, cantik sendalnya di kaki mbak". ( menyarankan)

e). Pedagang E

" boleh-boleh, lihat aja dulu kakak, mana yang kakak suka, pilih aja, pilih aja". (mengajak)

f). Pedagang $F \quad$ : "kakak pake pinggangnya no berapa?" (meminta)

g). Pedagang $\mathrm{G}$ : "awak samo awak agih duo limo ni, bahannya spandek ko mah ni 
dingin, lamak di pakai”.(menagih)

h). Pedagang $\mathrm{H}$ :

"ondeh yo alun dapek lai doh ni, alun pulang pokoknyo lai doh ni". (memberi aba-aba)

i). Pedagang I

"tambahlah lima ribu lagi kak". (meminta)

Berdasarkan hasil analisis data bahwa tindak tutur direktif ini digunakan oleh pedagang di pasar tanah abang dalam berkomunikasi dengan pembeli.

3. Tindak tutur ekspresif

Hal ini dapat kita temukan dalam tindak tutur pedagang dipasar tanah abang:
a). Pedagang A : lagi kembali kesini aja, hitung- hitung buat langganan". ( mengucapkan terima kasih)
"makasih banyak mbak, kalo ada
b). Pedagang B : saya belum dapat segitu".
"waduh belum dapat kak, modal (mengeluh)
c). Pedagang C : kulit kakak putih jadi masuk warnanya". ( memuji)
" tu bajunya pas banget kak, cantik kalo mbak yang pake, apa lagi
d). Pedagang D : segini kak. (menyalahkan)
"kalo di mole belum tentu dapat

Berdasarkan hasil analisis data diketahui bahwa tindak tutur ekspresif ini digunakan oleh pedagang kaki lima di pasar tanah abang dalam berkomunikasi dengan pembeli.

\section{Tindak tutur komisif}

Hal ini dapat kita temukan dalam tindak tutur pedagang di pasar tanah abang:
a). Pedagang A :
"kalo rusak saya kasih garansinya satu bulan kak. (berjanji)
b). Pedagang B :
"kalo jamnya mati pergantian baterainya saya kasih gratis mbak". (berjanji)
c). Pedagang $\mathrm{C}$ :
"demi tuhan mbak, selama ini barang dagangan saya bisa dijamin kualitasnya (bersumpah)

Berdasarkan hasil analisis data diketahui bahwa tindak tutur komisif ini digunakan oleh pedagang kaki lima di pasar tanah abang dalam berkomunikasi dengan pembeli.

\section{Tindak tutur deklaratif}

Hal ini dapat kita temukan dalam tindak tutur pedagang di pasar tanah abang:
a). Pedagang A :
"ya udah kasih lah kak. (memutuskan)
b). Pedagang B : masalahnya warnanya putih. (melarang)
"maaf ya kak itu gak bisa di coba,
c). Pedagang $\mathrm{C}$ :
"ya silahkan di coba aja dulu sendalnya mbak.(mengizinkan)

Berdasarkan hasil analisis data diketahui bahwa tindak tutur deklaratif ini digunakan oleh pedagang kaki lima di pasar tanah abang dalam berkomunikasi dengan pembeli.

Berdasarkan hasil penelitian dapat di simpulkan bahwa pedagang di pasar tanah abang menggunakan semua jenis tindak tutur yang dikemukakan oleh pendapat [5], namun dari kelima jenis tindak tutur, yang lebih banyak digunakan yaitu tindak tutur direktif, dimana tindak tutur ini bermaksud mengajak dan mempengaruhi pembeli.

\section{SIMPULAN}

Berdasarkan hasil analisis pada teori yang membagi tindak tutur atas lima jenis yaitu, representatif, komisif, ekspresif, direktif, dan deklaratif [5], maka dapat di peroleh 
1. Tindak tutur representatif

a). Pedagang $\mathrm{A}$ : "barang mangga dua itu mbak, kalo di malle itu seratus lebih lo mbak" ( menyatakan)

b). Pedagang B : "jamnya tahan air kak, dibawa berenang,mandi gak bakal mati”. (menunjukkan)

c). Pedagang $\mathrm{C}$ : "yang itu dua lima aja mbak, kalo ke orang tadi saya jual tiga puluh. ( menyebutkan)

d). Pedagang D : "bahannya bagus kak, kulit asli itu, dijamin kakak gak bakal merasa rugi".(melaporkan)

e). Pedagang E : "iko modalnyo se limo puluh ni, bahan stret ko mah ni". (menyatakan)

f). Pedagang F : "itu aja modalnya 30, bagaimana saya menjualnya 25 kak rugi mah yang ada saya".(menyebutkan)

g). Pedagang $\mathrm{G}$ : "boleh dilihat, ini buktinya jam yang sama saya rendam di air dari tadi”.(menunjukkan)

2. Tindak tutur direktif

a). Pedagang A : "ayo beli mbak, baju kaos murahmurah, dua dua lima”.(mengajak)

b). Pedagang B : "silahkan neng pilih aja jam tangannya, barisan depan dua lima, tengah kasih tiga puluh, dan belakang empat lima". (mengajak)

c). Pedagang $\mathrm{C}$ : "boleh di uji, lihat ini mbak jamnya saya rendam di air, gak mati.(menantang)

d). Pedagang D : "kalo jamnya mati, uang kakak saya kembalikan". (menantang)

e). Pedagang E : "dicoba aja dulu kak, kakinya nomor berapa? nah tu pas banget kan mbak, cantik sendalnya di kaki mbak.( menyarankan)

f). Pedagang F :

"boleh-boleh ;lihat aja dulu kakak, mana yang kakak suka, pilih aja, pilih aja". (mengajak)

g). Pedagang $\mathrm{G}$ : "kakak pake pinggangnya no berapa?" (m eminta)

h). Pedagang $\mathrm{H} \quad$ : "awak samo awak agih duo limo ni, bahannya spandek ko mah ni dingin, lamak di pakai (menagih)

i). Pedagang I : "ondeh yo alun dapek lai doh ni, alun pulang pokoknyo lai doh ni. (memberi aba-aba)

j). Pedagang J : "tambahlah lima ribu lagi kak. (meminta)

3. Tindak tutur ekspresif

a). Pedagang A : "makasih banyak mbak, kalo ada lagi kembali kesini aja,hitunghitung buat langganan. (mengucapkan terima kasih)

b). Pedagang B : "waduh belum dapat kak, modal saya belum dapat segitu. (mengeluh)

c). Pedagang $\mathrm{C}$ : "tu bajunya pas banget kak, cantik kalo mbak yang pake apa lagi kulit kakak putih jadi masuk warnanya. ( memuji)

d). Pedagang D : "kalo di mole belum tentu dapat segini kak (menyalahkan)

4. Tindak tutur komisif
a). Pedagang $\mathrm{A}$ :
"kalo rusak saya kasih garansinya satu bulan kak. (berjanji)
b). Pedagang B :
"kalo jamnya mati pergantian baterainya saya kasih gratis mbak. (berjanji)
c). Pedagang $\mathrm{C}$ :
"demi tuhan mbak, selama ini barang dagangan saya bisa


dijamin kualitasnya (bersumpah)

5. Tindak tutur deklaratif

a). Pedagang A : "ya udah kasih lah kak. (memutuskan)

b). Pedagang B : "maaf ya kak itu gak bisa di coba, masalahnya warnanya putih.(melarang)

c). Pedagang $\mathrm{C} \quad$ : "ya silahkan di coba aja dulu sendalnya mbak.(mengizinkan)

Berdasarkan hasil penelitian di pasar Tanah Abang dapat kita lihat tindak tutur yang digunakan saat berkomunikasi dalam kesehariannya dengan pembeli yaitu semua jenis tindak tutur yang di kemukakan dengan mengembangkan teori tindak tutur menjadi: tindak tutur representatif, tindak tutur direktif, tindak tutur ekspresif, tindak tutur komisif, dan tindak tutur deklaratif [8].

Namun dari kelima jenis tidak tutur yang di kemukakan yang lebih sering digunakan yaitu tindak tutur direktif. Karena tindak tutur direktif berfungsi meminta, memohon, mengharap, menawarkan, mengajak, membujuk, mendukung, dan mendesak.

\section{DAFTAR PUSTAKA}

[1] Chaer Abdul dan Leonie Agustina. Sosiolinguistik Perkenalan Awal. Jakarta: Rineka Cipta, 2010.

[2] Rusminto,Nurlaksana Eko. Analisis Wacana Kajian Teori dan Praktis. Yogyakarta: Graha Ilmu, 2015

[3] Chaer, Abdul. Tata Bahasa Praktis Bahasa Indonesia. Jakarta: Reneka Cipta, 1998.

[4] Austin, J.L.1962. How to Do Things With Words. Oxford New York. Oxford University Press.

[5] Ibrahim, Abdul Syukur. Kajian Tindak Tutur. Surabaya: Usaha Nasional, 1993.

[6] Rustono.Pokok-pokok Pragmatik. Semarang: CV IKIP Semarang Press, 1999.

[7] Sudaryanto. Metode Linguistik Kearah Memahami Metode Linguistik. Yogyakarta: Gajah Mada University Press, 1993.

[8] Leech, Geoffrey. Prinsip-prinsip Pragmatik. Diterjemahkan oleh M.D.D. Oka; pendamping Setyadi Setyapratama. Jakarta: Universitas Indonesia ( UI-Press), 1993 